\title{
Determination of Iodide, Iodate and Total Iodine in Natural Water Samples by HPLC with Amperometric and Spectrophotometric Detection, and Off-line UV Irradiation
}

\author{
Akira TaKeda, ${ }^{* \dagger}$ Hirofumi Tsukada, ${ }^{*}$ Yuichi TaKaKu, ${ }^{*}$ Naoya Satta, ${ }^{* *}$ Mitsuhisa Baba, $* * *$ \\ Toshihiro Shibata,* Hidenao Hasegawa,* Yusuke Unno,* and Shun'ichi Hisamatsu* \\ *Department of Radioecology, Institute for Environmental Sciences, 1-7 Ienomae, Obuchi, Rokkasho, \\ Kamikita, Aomori 039-3212, Japan \\ **Faculty of Agriculture, Iwate University, 3-18-8 Ueda, Morioka, Iwate 020-8550, Japan \\ ***School of Veterinary Medicine, Kitasato University, 23-35-1 Higashi, Towada, Aomori 034-8628, Japan
}

\begin{abstract}
We developed a rapid, simple method for the iodine speciation analysis of water and applied it to natural water samples. Simultaneous determinations of $\mathrm{I}^{-}$and $\mathrm{IO}_{3}{ }^{-}$were achieved with an HPLC system with amperometric detection for $\mathrm{I}^{-}$and spectrophotometric detection after a postcolumn reaction for $\mathrm{IO}_{3}{ }^{-}$. We determined the $\mathrm{I}^{-}$and $\mathrm{IO}_{3}{ }^{-}$concentrations in $20-\mu \mathrm{L}$ water samples within $10 \mathrm{~min}$. Total I concentrations in water samples were determined after the decomposition of organics by off-line UV irradiation for $30 \mathrm{~min}$, followed by reduction to $\mathrm{I}^{-}$. The analytical conditions were optimized by using test solutions rich in organic matter extracted from soils. We tested the new method with samples of groundwater, spring water, precipitation, soil percolate, stream water, and seawater as well as solutions extracted from soil. The method worked well, although the concentrations of some I species were below detection. This method is suitable for routine speciation analysis, which is important for studies of I behavior in the environment.
\end{abstract}

Keywords Dissolved organic iodine (DOI), HPLC, ICP-MS, iodate, iodide, speciation

(Received February 19, 2016; Accepted April 19, 2016; Published August 10, 2016)

\section{Introduction}

Iodine (I) is an essential micronutrient for the synthesis of thyroid hormones in humans; its deficiency causes goiter. Two billion individuals worldwide are estimated to have insufficient I in their diet. ${ }^{1}$ In contrast, the behavior of radioiodine released from nuclear facilities is of special concern because of its transferability in the environment and its ability to accumulate in the human thyroid. Radioiodine, especially ${ }^{129} \mathrm{I}$ (half-life $1.6 \times 10^{7} \mathrm{y}$ ) and ${ }^{131} \mathrm{I}$ (half-life $8.02 \mathrm{~d}$ ), is released into the atmosphere and ocean from nuclear facilities (e.g., nuclear fuel reprocessing plants). Understanding the behavior of radioiodine in the short and long terms is required to assess the radiation dose from these radionuclides. Stable iodine $\left({ }^{127} \mathrm{I}\right) \mathrm{can}$ be used as a natural analogue to predict the long-term behavior of ${ }^{129} \mathrm{I}$ in the environment. Iodine is found mainly as $\mathrm{I}^{-}, \mathrm{IO}_{3}^{-}$, and organic-I in the environment, and is easily transformed between these forms in response to changes of the environmental conditions. In the environment, chemical forms of I often change rapidly,,$^{2-8}$ and each species has a different mobility in environmental media. ${ }^{9-14}$ In the context of the movement of iodine via the liquid phase in terrestrial and aquatic environments,

$\dagger$ To whom correspondence should be addressed.

E-mail: takeda@ies.or.jp

H. T. present address: Institute of Environmental Radioactivity, Fukushima University, 1 Kanayagawa, Fukushima 960-1196, Japan. the speciation of I in liquids is a key to understanding its mobility.

Several methods have been developed to determine the forms of I in natural water samples. ${ }^{15}$ High-performance liquid chromatography (HPLC) can be used to separate $\mathrm{I}^{-}, \mathrm{IO}_{3}^{-}$, and other I species in liquid samples. An inductively coupled plasma mass spectrometer (ICP-MS) coupled with an HPLC or an ion chromatograph may be used to simultaneously determine $\mathrm{I}^{-}$and $\mathrm{IO}_{3}{ }^{-}$without the need for any pretreatment to convert the I species. ${ }^{16-21}$ In spite of the relatively low ionization efficiency of I, the sensitivity of an ICP-MS to I is satisfactory for the analysis of various types of natural-water samples. Although an HPLC-ICP-MS is widely recognized as a powerful tool for determining I speciation in water samples, it is not suitable for routine analysis in many laboratories because of the high cost of the instrument and of sample analysis. Machine time on an ICP-MS also generally tends to be inadequate because of competing demands for multi-element analyses for various purposes. In addition, coupling an HPLC and ICP-MS requires time-consuming and tedious work.

In an HPLC system, $\mathrm{I}^{-}$concentrations can be determined with several different detectors: UV spectrometers, ${ }^{22-25}$ fluorescence detectors, ${ }^{23}$ and electrochemical detectors. ${ }^{10,26,27}$ To determine the concentration of $\mathrm{IO}_{3}{ }^{-}$with an HPLC system, $\mathrm{IO}_{3}{ }^{-}$is converted to $\mathrm{I}^{-}$prior to analysis with a reducing agent, such as ascorbic acid. ${ }^{22,23,28-30}$ However, the process of reduction can result in an overestimation of the $\mathrm{IO}_{3}{ }^{-}$concentration in the solution, because other species of iodine, such as organic iodine, may be converted 


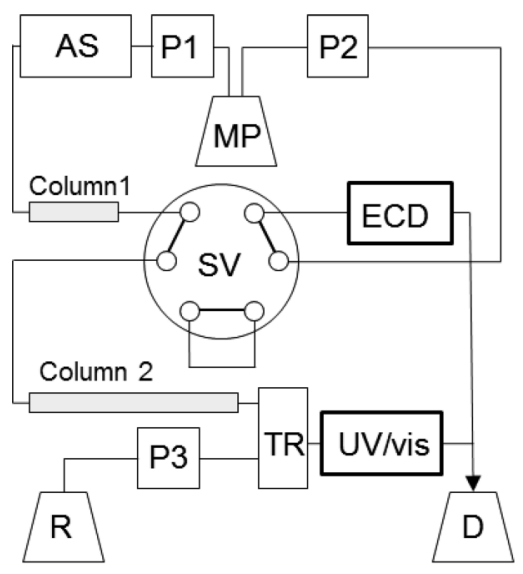

Position A

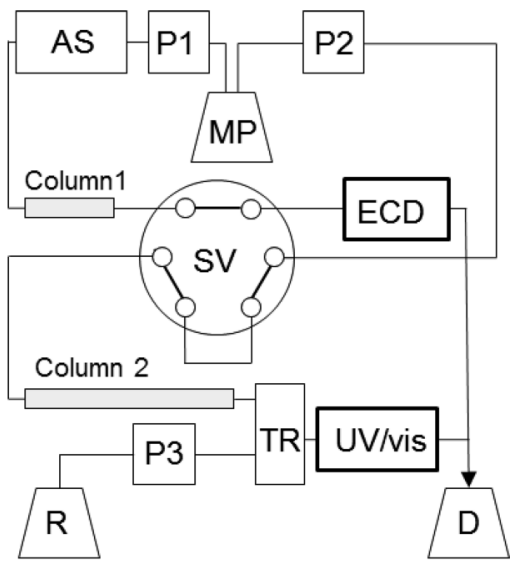

Position B

Fig. 1 Schematic diagram of the HPLC system for simultaneous determination of $\mathrm{I}^{-}$and $\mathrm{IO}_{3}{ }^{-}$. $\mathrm{P} 1$ and P2, pumps ( $\left.0.2 \mathrm{~mL} \mathrm{~min}^{-1}\right) ; \mathrm{P} 3$, pump $\left(0.09 \mathrm{~mL} \mathrm{~min}^{-1}\right)$; AS, autosampler (injection, $\left.20 \mu \mathrm{L}\right)$; column 1 , C8 column $(2 \times 35 \mathrm{~mm})$; column 2 , C18 column $(2 \times 250 \mathrm{~mm})$; SV, six-port switching valve (valves were switched from position A to B at a retention time of $2-8 \mathrm{~min})$; TR, thermoreactor $\left(90^{\circ} \mathrm{C}\right)$; ECD, electrochemical detector $(\mathrm{Ag} / \mathrm{AgCl},+50 \mathrm{mV})$; UV/vis, UV/visible light spectrometer $(450 \mathrm{~nm}) ; \mathrm{MP}$, mobile phase (20\% $\mathrm{CH}_{3} \mathrm{CN}, 50 \mathrm{mM} \mathrm{NaH}_{2} \mathrm{PO}_{4}, 10 \mathrm{mM}$ tetrabutylammonium phosphate); $\mathrm{R}$, reagent for postcolumn reaction (10\% ethanol, $1 \mathrm{M} \mathrm{HNO}_{3}, 100 \mathrm{mM} \mathrm{KBr}, 2 \mathrm{mM} o$-dianisidine); D, drain.

to $\mathrm{I}^{-}$in the process. In contrast, an HPLC postcolumn derivatization method with $o$-dianisidine has been widely used for the determination of $\mathrm{BrO}_{3}{ }^{-}$in drinking water ${ }^{31-33}$ and in bread. ${ }^{34}$ Because $\mathrm{IO}_{3}{ }^{-}$can also be sensitively detected by this method without the need to reduce $\mathrm{IO}_{3}{ }^{-35}$ we adopted this method for I speciation analysis of natural waters.

Dissolved organic-I (DOI) is considered to be one of the major forms of I in natural waters, and is often estimated to be the difference between the total $\mathrm{I}$ and inorganic $\mathrm{I}$ ( $\mathrm{I}^{-}$and $\left.\mathrm{IO}_{3}^{-}\right) \cdot 22,30,36,37$ ICP-MS systems have been widely used for direct determination of total I in natural water samples. ${ }^{38-41}$ Total I concentrations have also been determined after the decomposition of dissolved organic matter with HPLC systems designed to detect inorganic I. ${ }^{22,30}$ A UV-photooxidation technique is a powerful tool for decomposition of organic matter in natural water samples, ${ }^{42,43}$ and has been used for I analysis. ${ }^{44,45}$

In this study, we developed and applied a new method for the simultaneous determinations of $\mathrm{I}^{-}$and $\mathrm{IO}_{3}{ }^{-}$concentrations that is suitable for routine analysis of natural water samples without pretreatment. The method employs the combination of an HPLC coupled with amperometric detection for $\mathrm{I}^{-}$and spectrophotometric detection after postcolumn derivatization for $\mathrm{IO}_{3}{ }^{-}$. Organically bound $\mathrm{I}$ is also determined by subtracting the inorganic I concentration from the total I concentration. The latter was equated to the inorganic I concentration after pretreatment with a UV photo-oxidation step.

\section{Experimental}

\section{Reagents and chemicals}

Guaranteed reagent (GR)-grade sodium iodide (NaI), sodium iodate $\left(\mathrm{NaIO}_{3}\right)$, and potassium bromide $(\mathrm{KBr})$ were obtained from Merck (Darmstadt, Germany). Acetonitrile (HPLC grade), sodium dihydrogenphosphate $\left(\mathrm{NaH}_{2} \mathrm{PO}_{4}\right.$, GR grade), nitric acid (for toxic metal analysis) and $\mathrm{L}(+)$-ascorbic acid (GR grade) were obtained from Kanto Chemical (Tokyo, Japan). HPLCgrade ethanol and tetrabutylammonium dihydrogen phosphate (TBA) solution were obtained from Wako Pure Chemical Industries (Osaka, Japan). Ortho dianisidine (ODA) was obtained from Sigma-Aldrich (St. Louis, MO, USA). A tetramethylammonium hydroxide solution (TMAH, TAMAPURE-AA-100) was obtained from Tama Chemicals (Kawasaki, Japan).

Standard solutions (1000 mg- L L ${ }^{-1}$ of $\mathrm{I}^{-}$and $\mathrm{IO}_{3}^{-}$were prepared by the dissolution of $\mathrm{NaI}$ and $\mathrm{NaIO}_{3}$, respectively, in deionized water. Mixtures of standard solutions of $\mathrm{I}^{-}$and $\mathrm{IO}_{3}{ }^{-}$ were prepared from stock solutions before the analysis. The mobile phase of the HPLC system described below consisted of a solution of $20 \%(\mathrm{v} / \mathrm{v})$ acetonitrile and $80 \%(\mathrm{v} / \mathrm{v})$ deionized water with $50 \mathrm{mM} \mathrm{NaH}_{2} \mathrm{PO}_{4}$ and $10 \mathrm{mM}$ TBA. The solution for the postcolumn reaction consisted of $10 \%$ (v/v) ethanol, $1 \mathrm{M}$ $\mathrm{HNO}_{3}, 100 \mathrm{mM} \mathrm{KBr}$, and $2 \mathrm{mM}$ ODA. A solution of $0.2 \mathrm{M}$ ascorbic acid solution in deionized water was prepared before use.

\section{Apparatus}

An HPLC system (Nanospace SI-2, Shiseido, Tokyo, Japan) equipped with a UV/visible light absorption spectrometer (UV/ vis) (Model 3002, Shiseido) with a tungsten lamp (measurement wavelength for oxidized ODA, $450 \mathrm{~nm}$ ) and an electrochemical detector (ECD) (Model 3005, Shiseido) with an $\mathrm{Ag} / \mathrm{AgCl}$ electrode $(+50 \mathrm{mV})$ was used in this study. Two reverse-phase columns [Capcel Pak C8 DD $2.0 \times 50 \mathrm{~mm}(\mathrm{C} 8$ column) and Capcel Pak C18 MGII $2.0 \times 250 \mathrm{~mm}(\mathrm{C} 18$ column), Shiseido] were used as separation columns in the HPLC system. A UV irradiation system (Model 705 UV Digester, Metrohm AG, Herisau, Switzerland) was used for UV photolysis of dissolved organic matter in liquid samples.

The HPLC system was coupled with the UV/vis and ECD through a six-port switching valve (Model 3011, Shiseido) (Fig. 1). The flow rate of the mobile phase was adjusted to $0.2 \mathrm{~mL} \mathrm{~min}^{-1}$ with pumps. Two reverse-phase columns were serially connected via a six-port switching valve (Columns 1 and 2 in Fig. 1). A $20-\mu \mathrm{L}$ aliquot of the sample solution was injected through an autosampler. The $\mathrm{I}^{-}$and $\mathrm{IO}_{3}{ }^{-}$in the sample solution were separated in the first $\mathrm{C} 8$ column; $\mathrm{IO}_{3}{ }^{-}$eluted first, while $\mathrm{I}^{-}$was retained. Up to $2 \mathrm{~min}$ after the sample was introduced through the switching valve (position A in Fig. 1), the $\mathrm{IO}_{3}{ }^{-}$eluted into the second $\mathrm{C} 18$ column for further separation 
from other halogen oxoacids (e.g., $\mathrm{BrO}_{3}^{-}$and $\mathrm{ClO}_{2}^{-}$). The purified $\mathrm{IO}_{3}{ }^{-}$was reacted with $\mathrm{KBr}$ and ODA in a thermoreactor at $90^{\circ} \mathrm{C}$ for measuring the $450-\mathrm{nm}$ absorbance of oxidized ODA with the UV/vis. The $\mathrm{I}^{-}$eluted from the first column with a retention time of $2-8$ min was introduced through the six-port switching valve (position B in Fig. 1) into the ECD for direct measurements of its concentration.

To validate this analytical methodology, we assayed for $\mathrm{I}^{-}$and $\mathrm{IO}_{3}{ }^{-}$independently with the HPLC-ICP-MS system. The HPLC-ICP-MS system consisted of an HPLC system (LC1100; Agilent Technologies, Santa Clara, CA, USA) with an anionexchange column (IC-1, 4.6 × $100 \mathrm{~mm}$; GL Sciences, Tokyo, Japan) coupled with an ICP-MS (VG PQ Excel; Thermo Elemental, Winsford, UK). An aliquot of $100 \mu \mathrm{L}$ of sample water was injected into the column with a mobile phase of $50 \mathrm{mM} \mathrm{Na} \mathrm{CO}_{3}$ solution at a flow rate of $1.0 \mathrm{~mL} \mathrm{~min}{ }^{-1}$.

\section{Determination of total iodine}

For determining total I in the sample solution, we used UV irradiation to photodissociate the DOI. An aliquot of $1-10 \mathrm{~mL}$ of the sample solution was pipetted into a quartz tube. The tube was sealed with a silicon stopper and irradiated with UV light $(500 \mathrm{~W})$ at $60^{\circ} \mathrm{C}$. After irradiation for up to $60 \mathrm{~min}$, ascorbic acid was added to the sample solution to convert all I species to $\mathrm{I}^{-}$. The final concentration of ascorbic acid was $10 \mathrm{mM}$. The concentration of $\mathrm{I}^{-}$was determined with the HPLC-ECD system previously described in Apparatus. The concentration of total I in the sample solution was independently determined by ICPMS after diluting the solution with $0.25 \%$ (v/v) TMAH and adding $\mathrm{Cs}$ as an internal standard.

\section{Test solution for validation of the analytical system}

Solutions extracted with water from soils were used as test samples to validate the analytical system. Six soil samples collected from four different sites in Rokkasho, Aomori, Japan (Table S1) were used. Soils A and B were surface soils from different grasslands; soil $\mathrm{C}$ was collected from a broadleaf forest and contained a high concentration of I. Soils D1, D2, and D3 were collected from different depths of a coniferous forest soil profile and contained variable total carbon and I concentrations. The soil samples were dried in a drying oven at $50^{\circ} \mathrm{C}$ for 1 week and passed through 2-mm sieve. Total carbon concentrations in the soil samples were determined to be ranged from 13 to $97 \mathrm{~g} \mathrm{~kg}^{-1}$ by means of dry combustion method. The I concentrations in the soils were determined to be 8.7-90 $\mathrm{mg} \mathrm{kg}^{-1}$ by means of polarizing, energy-dispersive, X-ray fluorescence spectrometry. ${ }^{46}$ The I was extracted from the dried soils with water, and these aqueous solutions were used as test solutions for optimizing the analytical conditions. After an aliquot of the dried soil sample was shaken with deionized water (1:10 ratio of soil weight to water volume) for $1 \mathrm{~h}$, the supernatant was separated by centrifugation, and was filtered through $0.22-\mu \mathrm{m}$ pore size membrane filters. To assay test solutions rich in organic substances, a solution containing $0.01 \mathrm{M} \mathrm{NaOH}$ was also used to extract the I from soil A (Table S1), following the same protocol as that used for the deionized water extractions.

\section{Natural water samples}

The method developed for iodine analysis was used to analyze several natural-water samples collected in the eastern region of Aomori Prefecture, Japan (Table 1). Surface seawater samples were collected from coastal waters of the Pacific Ocean $\left(40^{\circ} 55^{\prime} \mathrm{N}, 141^{\circ} 23^{\prime} \mathrm{E}\right)$ and Mutsu Bay $\left(40^{\circ} 56^{\prime} \mathrm{N}, 140^{\circ} 51^{\prime} \mathrm{E}\right)$ in October 2013. A water sample from a spring was collected in
Table 1 Concentrations of $I$ species in spring water, groundwater, and seawater

\begin{tabular}{llccc}
\hline \multicolumn{1}{c}{ Sample } & \multicolumn{1}{c}{ Date } & $\begin{array}{c}\mathrm{I}^{-\mathrm{a} /} \\
\mu \mathrm{g}-\mathrm{I} \mathrm{L}^{-1}\end{array}$ & $\begin{array}{c}\mathrm{IO}^{-\mathrm{a} /} \\
\mu \mathrm{g}-\mathrm{I} \mathrm{L}^{-1}\end{array}$ & $\begin{array}{c}\text { Total I } \\
\mu \mathrm{g}-\mathrm{I} \mathrm{L}^{-1}\end{array}$ \\
\hline $\begin{array}{l}\text { Spring water } \\
\text { Goundwater }\end{array}$ & Jun. 24, 2014 & $<0.5$ & 11.4 & 16.7 \\
Seawater & Aug. 5, 2014 & 231 & $<1.0$ & 234 \\
Pacific Ocean & Oct. 7, 2013 & 13.7 & 36.9 & 51.5 \\
& Oct. 21, 2013 & 12.6 & 30.4 & 49.0 \\
Mutsu Bay & Oct. 8, 2013 & 13.5 & 31.8 & 51.3 \\
& Oct. 22, 2013 & 13.3 & 30.9 & 51.4 \\
\hline
\end{tabular}

a. Concentrations of $\mathrm{I}^{-}$and $\mathrm{IO}_{3}{ }^{-}$were determined simultaneously by HPLC.

b. Concentrations of total I were determined as $\mathrm{I}^{-}$after 30-min UV irradiation and reduction by addition of ascorbic acid.

the town of Takko $\left(40^{\circ} 17^{\prime} \mathrm{N}, 141^{\circ} 06^{\prime} \mathrm{E}\right)$ in June 2014 , and a groundwater sample was collected from a shallow well in the village of Rokkasho $\left(40^{\circ} 58^{\prime} \mathrm{N}, 141^{\circ} 21^{\prime} \mathrm{E}\right)$ in August 2014 with the use of a bailer sampler (Daiki Rika Kogyo, Saitama, Japan). The depth of the well was $25.8 \mathrm{~m}$, and the sampler collected water through a strainer from depths of $22.8-25.8 \mathrm{~m} .{ }^{47}$ Terrestrial water samples were also collected in the town of Shichinohe $\left(40^{\circ} 41^{\prime} \mathrm{N}, \quad 141^{\circ} 06^{\prime} \mathrm{E}\right)$ from a Japanese cedar (Cryptomeria japonica) stand described by Baba et al. ${ }^{48,49}$ Open bulk precipitation and canopy throughfall samples were collected using polypropylene funnels $(17 \mathrm{~cm}$ in diameter) that were set up $1 \mathrm{~m}$ above the ground and connected to polypropylene bottles. Samples of water that had percolated through soil were collected at various depths in the soil. Stainless, tension-free lysimeters $(13 \times 30 \mathrm{~cm})$ connected to polypropylene bottles were used for collection of soil percolate from just under the $\mathrm{O}$ horizon and from a depth of $10 \mathrm{~cm}$. A porous cup (Daiki Rika Kogyo) and a porous plate (27-cm in diameter, Soilmoisture Equipment Corp., Goleta, CA, USA) connected to a vacuum Erlenmeyer flask were used for collecting soil percolate at depths of 50 and $90 \mathrm{~cm}$, respectively. Soil percolate was collected from June to August 2013. Stream water samples were also collected from the Japanese cedar stand. All water samples were passed through $0.22-\mu \mathrm{m}$ pore size membrane filters and stored at $4{ }^{\circ} \mathrm{C}$ prior to analysis.

\section{Results and Discussion}

\section{Simultaneous determination of $\mathrm{I}^{-}$and $\mathrm{IO}_{3}^{-}$}

Typical HPLC chromatograms for standard solutions, which contained $\mathrm{I}^{-}, \mathrm{IO}_{3}^{-}$, or both, are shown in Fig. 2 together with chromatograms of blank solutions. Figure 2 depicts signals from both the ECD (upper subfigure) and UV/vis (lower subfigure). The chromatograms contained many ghost peaks caused by changes of the flow path with the switching valve as well as some unknown peaks. The peaks of $\mathrm{I}^{-}$and $\mathrm{IO}_{3}^{-}$, however, were clearly separated from the other peaks. The injected $\mathrm{I}^{-}$was detected by the ECD at a retention time of about $5.7 \mathrm{~min}$, and $\mathrm{IO}_{3^{-}}$was detected at about $6.3 \mathrm{~min}$ by the UV/vis. The $\mathrm{I}^{-}$and $\mathrm{IO}_{3}^{-}$were successfully separated by the column system, and there was no interference between the two peaks (Figs. 2B, 2C). Analysis of each sample was completed within $10 \mathrm{~min}$. Calibration curves for $\mathrm{I}^{-}$and $\mathrm{IO}_{3}^{-}$were linear over the ranges $0.5-25$ and $1.0-50 \mu \mathrm{g}-\mathrm{I} \mathrm{L}^{-1}$, respectively. The limit of detection of $\mathrm{I}^{-}$and $\mathrm{IO}_{3}^{-}$, evaluated from the calibration curves, 


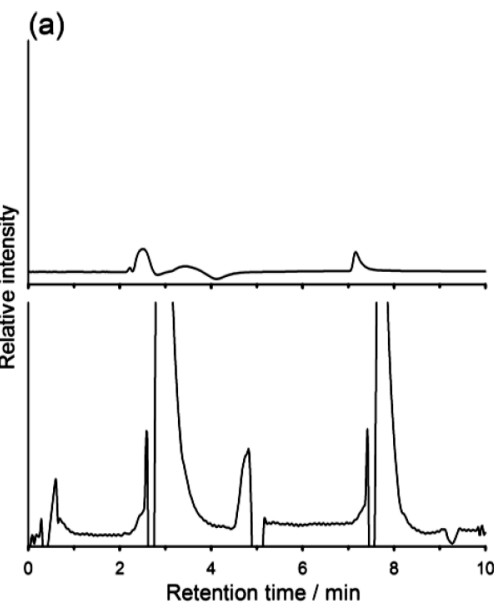

(c)

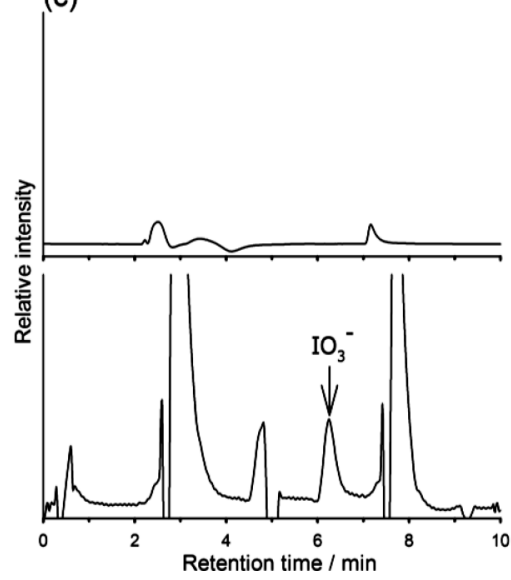

(b)

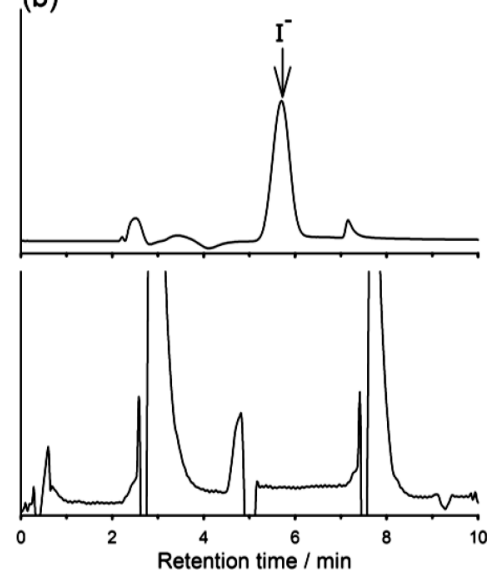

(d)

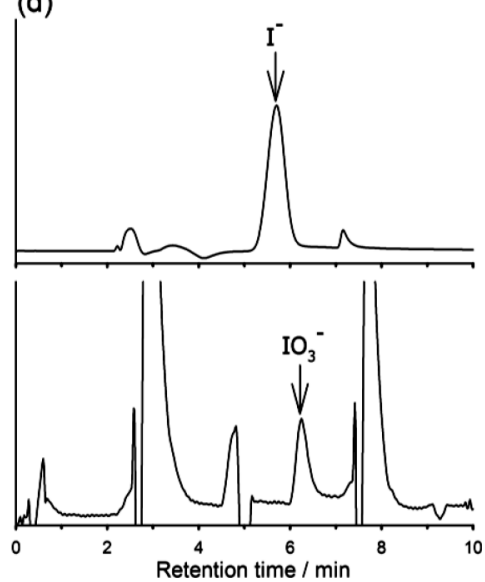

Fig. 2 HPLC chromatograms of standard solutions. (a) Blank solution; (b) standard solution of $\mathrm{I}^{-}$ $\left(25 \mu \mathrm{g}-\mathrm{I} \mathrm{L} \mathrm{L}^{-1}\right)$; (c) standard solution of $\mathrm{IO}_{3}{ }^{-}\left(50 \mu \mathrm{g}-\mathrm{I} \mathrm{L}^{-1}\right)$; (d) mixed standard solution of $\mathrm{I}^{-}$and $\mathrm{IO}_{3}{ }^{-}\left(\mathrm{I}^{-}\right.$, $\left.25 \mu \mathrm{g}-\mathrm{I} \mathrm{L}^{-1} ; \mathrm{IO}_{3}^{-}, 50 \mu \mathrm{g}-\mathrm{I} \mathrm{L}^{-1}\right)$. Upper subfigures, ECD for $\mathrm{I}^{-}$detection; lower subfigures, UV/vis for $\mathrm{IO}_{3}{ }^{-}$detection.

were 0.25 and $0.61 \mu \mathrm{g}-\mathrm{I} \mathrm{L}^{-1}$, respectively. The coefficients of variation for repeated measurements $(n=20)$ of $\mathrm{I}^{-}$and $\mathrm{IO}_{3}{ }^{-}$in a mixed solution of $\mathrm{I}^{-}\left(10 \mu \mathrm{g}-\mathrm{I} \mathrm{L}^{-1}\right)$ and $\mathrm{IO}_{3}{ }^{-}\left(20 \mu \mathrm{g}-\mathrm{I} \mathrm{L}^{-1}\right)$ were 2 and $4 \%$, respectively. To check for interference by other halogen oxoacids, a mixed solution of $\mathrm{ClO}_{2}^{-}, \mathrm{BrO}_{3}^{-}$, and $\mathrm{IO}_{3}^{-}$was analyzed. The $\mathrm{IO}_{3}^{-}$peak was cleanly separated from the other peaks (Fig. S1).

\section{Solution extracted with water from the soils}

The solutions extracted with water from the six soils were used as test solutions to check the applicability of the present methods to DOC-rich water samples (Table S1). The concentrations of the total I in the extracted solutions determined by the ICP-MS were $3-30 \mu \mathrm{g} \mathrm{L}^{-1}$, the indication being that $0.1-1.1 \%$ of the I in the soils was water-soluble.

We used the speciation results of I determined with the HPLCICP-MS as a reference for checking the HPLC-ECD system. Figure 3 shows typical HPLC-ICP-MS chromatograms of the standard $\mathrm{I}^{-}$and $\mathrm{IO}_{3}{ }^{-}$mixed solution and the solution extracted with water. With this analytical system, $\mathrm{I}^{-}$and $\mathrm{IO}_{3}^{-}$in the standard solution were clearly separated and detected with satisfactory sensitivity. In the water extract from soil A, no peak was detected other than $\mathrm{I}^{-}$. Because the difference between the total $\mathrm{I}$ and $\mathrm{I}^{-}$concentrations in the sample was large (13 $\mu \mathrm{g}-\mathrm{I} \mathrm{L}^{-1}$ in Table S1), the DOI probably adsorbed irreversibly to the anion-exchange column. In contrast, $\mathrm{I}^{-}$and an unknown broad peak were detected in the water extract from soil B. The concentration of $\mathrm{I}^{-}$was $9.1 \mu \mathrm{g}-\mathrm{I} \mathrm{L}^{-1}$, and the area under the unknown peak was equivalent to $8.3 \mu \mathrm{g}-\mathrm{I} \mathrm{L}^{-1}$. The sum of the concentrations associated with these two peaks accounted for $92 \%$ of the total I concentration in the solution. In the case of the water extract from soil $\mathrm{C}$, small, unknown peaks were detected at retention times of $6-9$ min, though their peak areas were much smaller than that of $\mathrm{I}^{-}$. In other soils (soils D1, D2, and D3), the shapes of the chromatograms (not shown in Fig. 3) were similar to those of soils A and C. These observations reflect the complexity of the dissolved I species in the soils. Reifenhäuser and Heumann ${ }^{44}$ have reported the presence of two types of DOI in natural water samples: anionic DOI elutable from the anion-exchange column and non-elutable DOI. The variation of the two kinds of DOI in our study is consistent with their results.

The contribution of $\mathrm{I}^{-}$to the total $\mathrm{I}$ of the extracted solutions was $27-63 \%$; $\mathrm{IO}_{3}{ }^{-}$was not detected in any of the solutions extracted with water from soils. These results suggest that DOI, which we estimated from the difference between the total I and the sum of $\mathrm{I}^{-}$and $\mathrm{IO}_{3}^{-}$, and $\mathrm{I}^{-}$were the predominant forms of $\mathrm{I}$ in the extracted solution.

The concentrations of $\mathrm{I}^{-}$and $\mathrm{IO}_{3}{ }^{-}$in the solution extracted from the soils were determined simultaneously with the HPLC system (Fig. 1) developed in this study. The $\mathrm{IO}_{3}{ }^{-}$concentrations of all the samples were found to be below the limit of detection. 


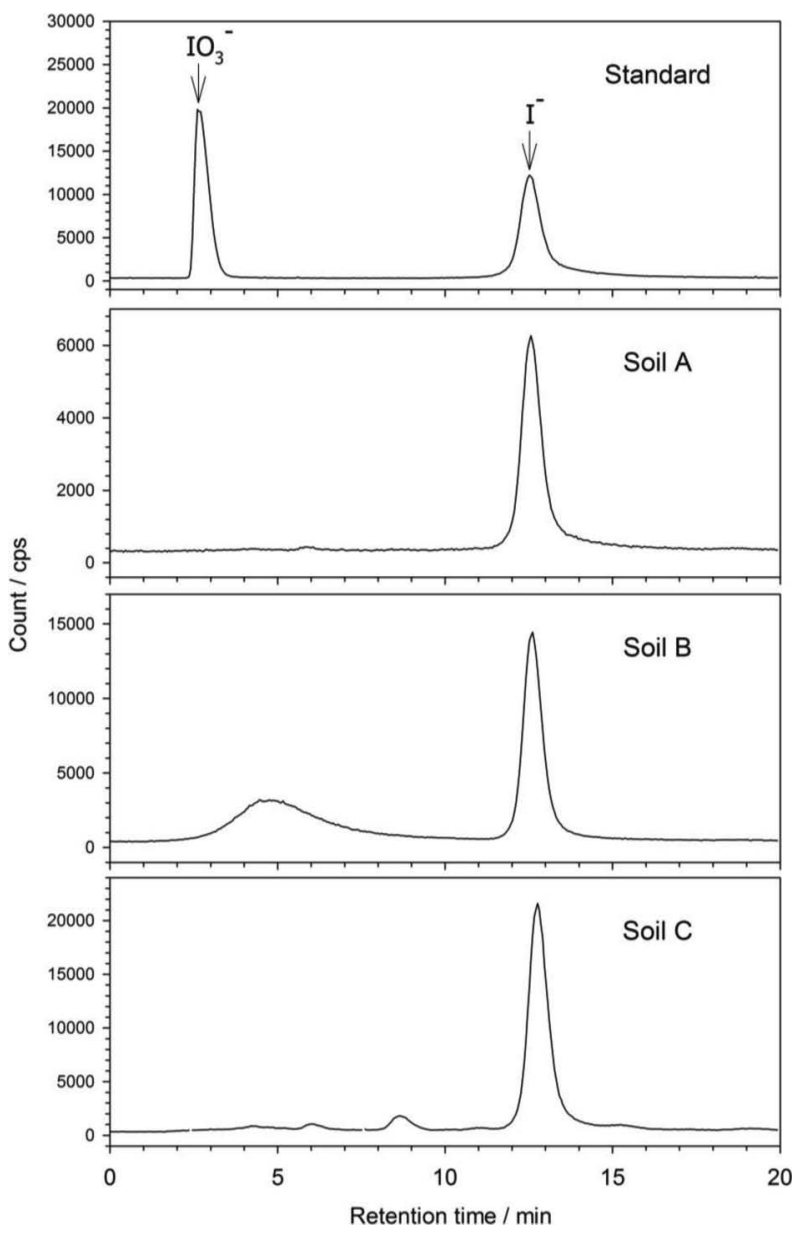

Fig. 3 HPLC-ICP-MS chromatograms of a mixed standard solution $\left(\mathrm{I}^{-}, 10 \mu \mathrm{g}-\mathrm{I} \mathrm{L}^{-1} ; \mathrm{IO}_{3}^{-}, 10 \mu \mathrm{g}-\mathrm{I} \mathrm{L}^{-1}\right)$ and water extract from soils.

Figure 4 compares the concentrations of $\mathrm{I}^{-}$in the extracted solutions determined with the HPLC-ECD and HPLC-ICP-MS methods. The concentrations of $\mathrm{I}^{-}$determined by the two methods were in good agreement. The HPLC-ECD system can therefore be used to assay for $\mathrm{I}^{-}$in soil extracts that contain relatively high DOC concentrations.

\section{Determination of total I in solution by UV irradiation}

We irradiated the water-extracted solution from soil A to test the efficiency of DOI photolysis by UV. To optimize the UV-irradiation time, the solutions were irradiated for 0 - $60 \mathrm{~min}$, and their post-irradiation DOC and $\mathrm{I}^{-}$concentrations were determined after addition of ascorbic acid as a reducing agent. Figure 5 shows the DOC and $\mathrm{I}^{-}$concentrations as a function of the UV irradiation time. The water extract from soil A contained $4.5 \mu \mathrm{g}-\mathrm{I} \mathrm{L}^{-1}$ of $\mathrm{I}^{-}$and $<1.0 \mu \mathrm{g}-\mathrm{I} \mathrm{L}^{-1}$ of $\mathrm{IO}_{3}^{-}$(Table S1). The concentration of $\mathrm{I}^{-}$increased to $8.0 \mu \mathrm{g}-\mathrm{I} \mathrm{L}^{-1}$ after the addition of ascorbic acid solution without UV irradiation (time of 0 in Fig. 5). These results suggest that some species of I other than $\mathrm{IO}_{3}^{-}$was converted to $\mathrm{I}^{-}$by nothing more than the addition of ascorbic acid. The concentration of $\mathrm{I}^{-}$in the water extract increased after $10 \mathrm{~min}$ of irradiation, but remained constant after further irradiation. In contrast, although the DOC concentrations in these soil extracts continued to decrease with irradiation time, $\sim 1 / 3$ of the DOC still remained after $60 \mathrm{~min}$ of irradiation. These results suggest that the DOI in the solution was sensitive to UV irradiation, and the conversion of DOI to

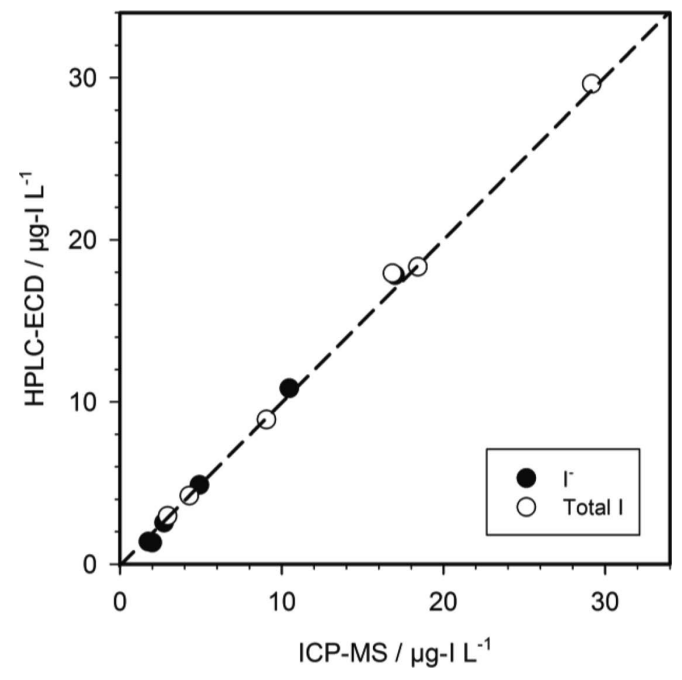

Fig. 4 Comparison of the method developed in this study (HPLCECD) and the ICP-MS method for $\mathrm{I}^{-}$and total I concentrations in water extracts from soils.
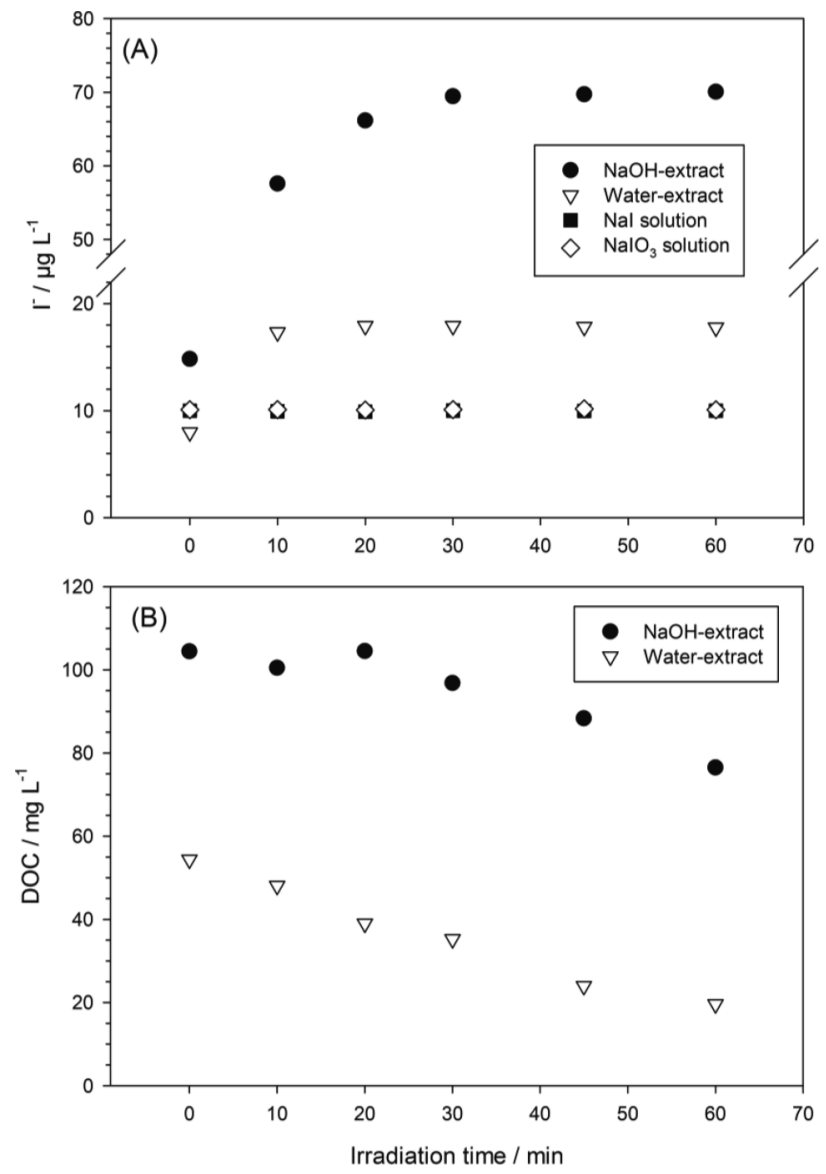

Fig. 5 Changes of $\mathrm{I}^{-}$and dissolved organic carbon (DOC) concentrations in standard solution $\left(10 \mu \mathrm{g}-\mathrm{I} \mathrm{L}^{-1}\right.$ of $\mathrm{I}^{-}$or $\left.\mathrm{IO}_{3}^{-}\right)$and aqueous extract from soil A after different UV-irradiation times. Concentrations of $\mathrm{I}^{-}$were determined after addition of ascorbic acid. Each plot indicates mean values of duplicate treatments.

$\mathrm{I}^{-}$by this methodology proceeded more rapidly than the photolysis of dissolved organic carbon.

To check the efficiency of total I detection by this method, 


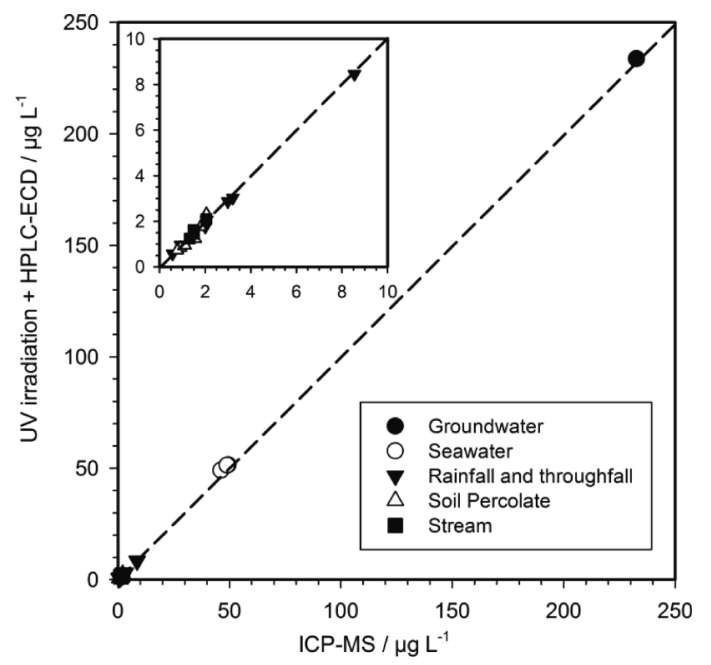

Fig. 6 Comparison of the method developed in this study (UV irradiation + HPLC-ECD) and the ICP-MS method for total I concentrations in various natural water samples.

the total I concentrations in the solutions extracted with water from the six soils were determined by using UV irradiation for $30 \mathrm{~min}$, and compared with the concentrations determined by using ICP-MS (Fig. 4). The results obtained with the UV-irradiation and ICP-MS methods agreed well with one another. Total I in the water-extracted soil solution was therefore completely recovered with the UV-irradiation method.

To confirm the applicability of the present method to water samples with higher DOC concentrations, we assayed a solution extracted with $0.01 \mathrm{M} \mathrm{NaOH}$ from soil A for DOC and total I concentrations after UV irradiation for times up to $60 \mathrm{~min}$ (Fig. 5). The $\mathrm{I}^{-}$concentration in the extract initially increased and reached a constant value after $30 \mathrm{~min}$ of irradiation. Based on these results, 30 min was selected as the irradiation time, and was used in subsequent analyses of total I in water samples.

Finally, the stability of $\mathrm{I}^{-}$and $\mathrm{IO}_{3}{ }^{-}$in the irradiated solution was tested by using a standard solution of both species. The results (Fig. 5A) showed that the recovery of both species was complete and was unaffected by UV irradiation time.

Wong and Cheng ${ }^{45}$ have recommended the addition of $\mathrm{H}_{2} \mathrm{O}_{2}$ and three hours of irradiation to convert DOI to $\mathrm{IO}_{3}{ }^{-}$in seawater samples. In the procedure described here, $30 \mathrm{~min}$ of irradiation without addition $\mathrm{H}_{2} \mathrm{O}_{2}$ was acceptable as a pretreatment for the determination of total $\mathrm{I}$ by a post-irradiation measurement of $\mathrm{I}^{-}$.

\section{Application to various natural water samples}

The method reported here for I speciation analysis with an HPLC system was applied to various natural water samples (Table 1 and Table S2). The total I concentrations in the water samples determined by HPLC analysis after UV irradiation were in good agreement with those determined by ICP-MS over a wide range of concentrations (Fig. 6).

In the spring water sample, the concentration of total I was 16.7 $\mu \mathrm{g}-\mathrm{I} \mathrm{L}^{-1}$, and $\mathrm{I}^{-}$was not detected (Table 1). The predominant species of $\mathrm{I}$ in the sample was $\mathrm{IO}_{3}^{-}$, which accounted for $69 \%$ of the total I; DOI accounted for at least $28 \%$.

The total I concentration in the groundwater sample, which had a low dissolved oxygen concentration ( $6.4 \%$ of saturation) and oxidation-reduction potential $(+78 \mathrm{mV})$, was $234 \mu \mathrm{g}-\mathrm{I} \mathrm{L}^{-1}$, the highest total I concentration measured in this study (Table 1). That most of the dissolved I in the sample was present as $\mathrm{I}^{-}$is a reflection of the anoxic condition of the aquifer.

Although seawater samples required a ten-fold dilution before analysis due to a high salt concentration, both $\mathrm{I}^{-}$and $\mathrm{IO}_{3}{ }^{-}$were detected. The total I concentration in the seawater samples ranged from 49.0 to $51.5 \mu \mathrm{g}-\mathrm{I} \mathrm{L}^{-1}$, with $\mathrm{IO}_{3}{ }^{-}$being the dominant species (Table 1): the $\mathrm{I}^{-}$and $\mathrm{IO}_{3}^{-}$accounted for $26-27 \%$ and $60-75 \%$, respectively, of the total I. Total inorganic iodine accounted for $86-98 \%$ of the total I, the implication being that $2-14 \%$ of iodine existed as DOI. Similar observations were reported in previous studies in coastal surface seawater samples. $^{21}$

Concentrations of iodine species in various water samples, including precipitation, soil percolate, and stream water collected from the Japanese cedar stand, were determined by the HPLC-ECD method developed in this study. The results are given in Table S2. The samples of precipitation, soil percolate, and stream water had relatively low total I concentrations compared to the other water samples listed in Table 1 ; $\mathrm{IO}_{3}{ }^{-}$was not detected in any of the samples.

In the bulk precipitation samples collected from an open field, the total I concentration ranged from 0.58 to $2.07 \mu \mathrm{g}-\mathrm{I} \mathrm{L}^{-1}$. The total I concentrations in throughfall collected during the same sampling period were $3.0-4.1$ times the concentrations in bulk precipitation. Measurable total I concentrations were found in all precipitation samples. That inorganic iodine species were not detected in most of the same samples indicates that inorganic species accounted for a small fraction of the total I.

The concentrations of total $\mathrm{I}$ in the soil percolate samples collected from just below the $\mathrm{O}$ horizon and at a depth of $10 \mathrm{~cm}$ ranged from 0.72 to $2.32 \mu \mathrm{g}-\mathrm{I} \mathrm{L}^{-1}$. The soil percolates from just under the $\mathrm{O}$ horizon had relatively high total I concentrations compared to those from a depth of $10 \mathrm{~cm}$. Total I was not detected in any soil percolates from deeper soil. Total I concentrations determined by ICP-MS were $0.27-0.30 \mu \mathrm{g}-\mathrm{I} \mathrm{L}^{-1}$ and $0.09-0.14 \mu \mathrm{g}-\mathrm{I} \mathrm{L}^{-1}$ at depths of 50 and $90 \mathrm{~cm}$, respectively. There was thus a tendency for the total I concentration to decrease with increasing soil depth. The method developed in this study was not sensitive enough to detect the total I at such low concentrations. In stream water, the concentrations of total I were $1.24-2.10 \mu \mathrm{g}-\mathrm{I} \mathrm{L}^{-1}$, and inorganic I was undetectable.

The concentrations of total $\mathrm{I}$ in precipitation (bulk and throughfall) samples were positively correlated with DOC concentrations $(r=0.97, n=8)$. Similarly, the concentrations of total $\mathrm{I}$ in the soil percolate collected just below the $\mathrm{O}$ horizon and at a depth of $10 \mathrm{~cm}$ were also positively correlated with the DOC concentrations $(r=0.82, n=6)$ (Fig. S2). Although I species could have changed during the sampling period in the precipitation and soil percolate samples, these observations suggest that the behavior of I is strongly influenced by that of dissolved organic matter in the surface soil environment in this area. Knowledge of the characteristics of DOI would improve our understanding of the I behavior, especially in terrestrial environments.

\section{Conclusions}

A new method for the analysis of I speciation in various natural water samples was developed. In this method; only $20-\mu \mathrm{L}$ samples are required, and $\mathrm{I}^{-}$and $\mathrm{IO}_{3}{ }^{-}$are successfully determined in the same sample within 10 min by using an HPLC system with two different detectors and a column-switching valve. This simple and high-throughput analytical system is useful for routine analysis of I speciation, which requires rapid analysis after collecting samples of natural water. Total I was also 
determined after 30-min of UV irradiation and reduction to $\mathrm{I}^{-}$. These methods are more cost-effective than an ICP-MS system, and are applicable to many types of natural-water samples without any complex pretreatment. Although the sensitivity of this system needs to be improved for some water samples with relatively low concentration of I species, it can be used as an alternative to HPLC-ICP-MS for I speciation analysis of a variety of water samples.

\section{Acknowledgements}

The authors are grateful to Prof. H. Yamada (Kyoto Prefectural University) for his useful advice on the development of the analytical system. The authors thank Ms. Y. Uetake, Mr. S. Nakagawa, and Ms. K. Taneichi (ZAX, Inc.) for assistance with this research, and the analytical chemistry staff at Entex, Inc. for their support of the ICP-MS analysis. This work was carried out under a contract with the Aomori Prefectural Government, Japan.

\section{Supporting Information}

Supporting Information is available free of charge on the Web at http://www.jsac.or.jp/analsci/.

\section{References}

1. M. B. Zimmermann, P. L. Jooste, and C. S. Pandav, Lancet, 2008, 372, 1251.

2. K. Yuita, Soil Sci. Plant Nutr., 1992, 38, 281.

3. M. Seki, J. Oikawa, T. Taguchi, T. Ohnuki, Y. Muramatsu, K. Sakamoto, and S. Amachi, Environ. Sci. Technol., 2012, 47, 390.

4. Y. S. Shimamoto, Y. Takahashi, and Y. Terada, Environ. Sci. Technol., 2011, 45, 2086.

5. A. Takeda, H. Tsukada, M. Takahashi, Y. Takaku, and S. Hisamatsu, Radiat. Prot. Dosim., 2015, 167, 181.

6. N. Yamaguchi, M. Nakano, R. Takamatsu, and H. Tanida, $J$. Environ. Radioact., 2010, 101, 451.

7. N. Yamaguchi, M. Nakano, H. Tanida, H. Fujiwara, and N. Kihou, J. Environ. Radioact., 2006, 86, 212.

8. K. Yuita, N. Kihou, S. Yabusaki, Y. Takahashi, T. Saitoh, A. Tsumura, and H. Ichihashi, Soil Sci. Plant Nutr., 2005, 51, 1011.

9. H. P. Emerson, C. Xu, Y.-F. Ho, S. Zhang, K. A. Schwehr, M. Lilley, D. I. Kaplan, P. H. Santschi, and B. A. Powell, Appl. Geochem., 2014, 45, 105.

10. Q. Hu, P. Zhao, J. E. Moran, and J. C. Seaman, J. Contam. Hydrol., 2005, 78, 185.

11. W. Shetaya, S. Young, M. Watts, E. Ander, and E. Bailey, Geochim. Cosmochim. Acta, 2011, 77, 457.

12. Y. S. Shimamoto, T. Itai, and Y. Takahashi, J. Geochem. Explor, 2010, 107, 117.

13. C. Xu, D. I. Kaplan, S. Zhang, M. Athon, Y.-F. Ho, H.-P. Li, C. M. Yeager, K. A. Schwehr, R. Grandbois, and D. Wellman, J. Environ. Radioact., 2015, 139, 43.

14. S. Yoshida, Y. Muramatsu, and S. Uchida, Radiochim. Acta, 1998, 82, 293.

15. A. Moreda-Piñeiro, V. Romarís-Hortas, and P. BermejoBarrera, J. Anal. At. Spectrom., 2011, 26, 2107.

16. B. S. Gilfedder, M. Petri, and H. Biester, Atmos. Chem. Phys., 2007, 7, 2661.
17. N. Kozai, T. Ohnuki, and T. Iwatsuki, Water Res., 2013, 47, 1570.

18. V. Salov, J. Yoshinaga, Y. Shibata, and M. Morita, Anal. Chem., 1992, 64, 2425.

19. H. Yamada, I. Hisamori, and K. Yonebayashi, Soil Sci. Plant Nutr., 2002, 48, 379.

20. S. Yoshida, Y. Muramatsu, S. Katou, and H. Sekimoto, $J$. Radioanal. Nucl. Chem., 2007, 273, 211.

21. J. Zheng, M. Yamada, and S. Yoshida, J. Anal. At. Spectrom., 2011, 26, 1790.

22. K. Schwehr and P. Santschi, Anal. Chim. Acta, 2003, 482, 59.

23. H. Yamada, S. Kajiyama, and K. Yonebayashi, Bunseki Kagaku, 1995, 44, 1027.

24. K. Ito, Anal. Chem., 1997, 69, 3628.

25. K. Ito, J. Chromatogr. A, 1999, 830, 211.

26. T. K. Malongo, S. Patris, P. Macours, F. Cotton, J. Nsangu, and J. M. Kauffmann, Talanta, 2008, 76, 540.

27. H. Below and H. Kahlert, Fresenius J. Anal. Chem., 2001, $371,431$.

28. A. Lucia and M. Campos, Mar. Chem., 1997, 57, 107.

29. S. Zhang, K. Schwehr, Y.-F. Ho, C. Xu, K. Roberts, D. Kaplan, R. Brinkmeyer, C. Yeager, and P. Santschi, Environ. Sci. Technol., 2010, 44, 9042.

30. H. Yamada, M. Sugahara, H. Kosaka, A. Katayama, K. Takahashi, and K. Yonebayashi, Soil Sci. Plant Nutr., 1996, 42, 367.

31. S. Echigo, R. A. Minear, H. Yamada, and P. E. Jackson, $J$. Chromatogr. A, 2001, 920, 205.

32. H. P. Wagner, B. V. Pepich, D. P. Hautman, and D. J. Munch, J. Chromatogr. A, 1999, 850, 119.

33. C. R. Warner, D. H. Daniels, F. L. Joe Jr, and G. W. Diachenko, Food Addit. Contam., 1996, 13, 633.

34. K. Himata, M. Noda, S. Ando, and Y. Yamada, Food Addit. Contam., 1997, 14, 809.

35. B. Zhu, Z. Zhong, and J. Yao, J. Chromatogr. A, 2006 , $1118,106$.

36. K. Schwehr, P. Santschi, and D. Elmore, Limnol. Oceanogr.: Methods, 2005, 3, 326.

37. K. Schwehr, P. Santschi, D. Kaplan, C. Yeager, and R. Brinkmeyer, Environ. Sci. Technol., 2009, 43, 7258.

38. Y. Takaku, T. Shimamura, K. Masuda, and Y. Igarashi, Anal. Sci., 1995, 11, 823.

39. H. Yamada, T. Kiriyama, and K. Yonebayashi, Soil Sci. Plant Nutr., 1996, 42, 859.

40. K. Tagami and S. Uchida, At. Spectrosc., 2005, 26, 209.

41. J. Zheng, H. Takata, K. Tagami, T. Aono, K. Fujita, and S. Uchida, Microchem. J., 2012, 100, 42.

42. J. Golimowski and K. Golimowska, Anal. Chim. Acta, 1996, 325, 111.

43. M. Kolb, P. Rach, J. Schäfer, and A. Wild, Fresenius J. Anal. Chem., 1992, 342, 341.

44. C. Reifenhäuser and K. G. Heumann, Fresenius J. Anal. Chem., 1990, 336, 559.

45. G. T. F. Wong and X. H. Cheng, Mar. Chem., 1998, 59, 271.

46. A. Takeda, S. Yamasaki, H. Tsukada, Y. Takaku, S. Hisamatsu, and N. Tsuchiya, Soil Sci. Plant Nutr., 2011, 57, 19.

47. H. Hasegawa, S. Ueda, N. Akata, H. Kakiuchi, and S. Hisamatsu, Radiat. Prot. Dosim., 2015, 167, 201.

48. M. Baba, S. Abe, M. Kasai, T. Sugiura, and H. Kobayashi, J. Forest Res., 2011, 16, 446.

49. M. Baba, M. Kato, T. Sugiura, and H. Kobayashi, Soil Sci. Plant Nutr., 2004, 50, 403. 